\title{
Photosynthesis and the dynamics of oxygen consumption in a microbial mat as calculated from transient oxygen microprofiles
}

\author{
Eric H. G. Epping, ${ }^{1}$ Arzhang Khalili, and Roland Thar
}

Max-Planck-Institut für Marine Mikrobiologie, Microsensor Group, Celsiusstraße 1, 28359 Bremen, Germany

\begin{abstract}
A new method is presented to determine the rates of oxygen consumption, net oxygen metabolism (defined as photosynthesis minus oxygen consumption), and gross photosynthesis at high vertical resolution in benthic phototrophic communities. The rates of oxygen consumption and of net oxygen metabolism as a function of depth and time are calculated from the dynamics in oxygen concentration, as measured with oxygen microsensors during light-dark cycles, by numerically solving the general non-steady state diffusion-reaction equation. The results, as obtained for a temperate intertidal microbial mat, strongly suggest that the vertical distribution and the dynamics in oxygen consumption are controlled by the supply of both oxygen and oxidizable substrates from different sources. The depth distribution of gross photosynthesis, as obtained by the cycling procedure, showed reasonable agreement with the photosynthesis profile, as measured with the conventional light-dark shift method prior to the light-dark cycling experiment, thus supporting the applicability of the method.
\end{abstract}

Oxygenic photosynthesis often represents the major process for primary production in microbial mats, yielding oxygen, biomass, and low-weight organic molecules that may be excreted by the phototrophs as photosynthate (Bauld and Brock 1974; Bateson and Ward 1988). The rate of gross photosynthesis in terms of oxygen evolution rate can be measured with high vertical resolution by the oxygen microsensor light-dark shift technique (Revsbech et al. 1981; Revsbech and Jørgensen 1983). In contrast, no method is available for the direct measurement of oxygen respiration or total oxygen consumption in undisturbed microbial communities. Therefore, oxygen consumption rates, be it per unit surface area or volume of mat, can only be determined indirectly by balancing net gains and losses for oxygen. For illuminated benthic phototrophic communities, gross photosynthesis and oxygen fluxes into the layer can be qualified as gains, whereas oxygen consumption and fluxes out of the layer are to be considered as loss terms. Assuming steady state processes, this approach has been followed in several studies (e.g., Jensen and Revsbech 1989; Glud et al. 1992; Kühl et al. 1996), while Revsbech et al. (1986) used a nu-

\footnotetext{
${ }^{1}$ Present address: Netherlands Institute for Sea Research, P.O. Box 59, 1790 Den Burg, The Netherlands.

\section{Acknowledgements}

This work is a tribute to Hans van Gemerden, who through his lectures inspired us to explore the effect of dynamic light conditions on microbial activities in microbial mats.

The skillful construction of microsensors by Gaby Eickert, Anja Eggers, and Vera Hübner is greatly appreciated, as well as their patience in showing us how to construct them. Jörg Rethmeier is thanked for his advice on suitable locations for the sampling of intertidal microbial mats. Michael Kühl is thanked for the fruitful discussions on photosynthesis and oxygen consumption in microbial mats and for many other things besides. Wim van Raaphorst, Peter Berg, and an anonymous reviewer are gratefully acknowledged for carefully reviewing the manuscript. Part of this study was supported by the Red-Sea Research Programme, Project E, Microbial activities in hypersaline interfaces controlling nutrient fluxes, financed by the German Ministry for Research and Development.
}

merical procedure to solve the non-steady state diffusionreaction equations.

The changing chemical conditions in a microbial mat following a switch in light condition, e.g., $\mathrm{pH}$, the concentration of oxygen, of organic carbon, and of inorganic reduced compounds, may affect the metabolic activities and the kinetics of chemical reactions that involve oxygen. Therefore, a timedependent oxygen metabolism can be anticipated upon a change in light condition until a new stationary condition is attained. In this study, we present the dynamics in oxygen consumption and in net oxygen metabolism (defined as photosynthesis minus oxygen consumption) in a microbial mat following a switch in light condition. From these dynamics in activity, inferences will be made on the sources of substrates for oxygen consumption and the relative contributions of these substrates to oxygen consumption in a temperate intertidal microbial mat.

\section{Materials and methods}

Sample collection and storage-Microbial mat samples were collected from Wismar Bight, a sheltered brackish intertidal area on the German Baltic Sea coast. Samples were taken in October during low tide by use of acrylic liners (inner diameter $5.9 \mathrm{~cm}, 25 \mathrm{~cm}$ length). The salinity was 15.4 and the water temperature was $21^{\circ} \mathrm{C}$. The cores were transported to the laboratory and incubated in an aquarium while submersed in aerated water from the sampling site. The aquarium was placed in a greenhouse to keep the mat under a light regimen as close to in situ as possible until the start of the experiment. The sandy sediment was covered with a well-developed, clearly laminated microbial mat. The surface of this 3-4-mm thick organic layer consisted of a thin film of pennate diatoms. Underneath, a ca. 1-mm-thick dark green layer of cyanobacteria and a ca. 0.5-mm-thick pink layer of purple sulfur bacteria were observed. An intensively black-colored layer of 3-5 $\mathrm{mm}$ formed the transition between the organic rich surface layer and the grayish sandy sediment below. 


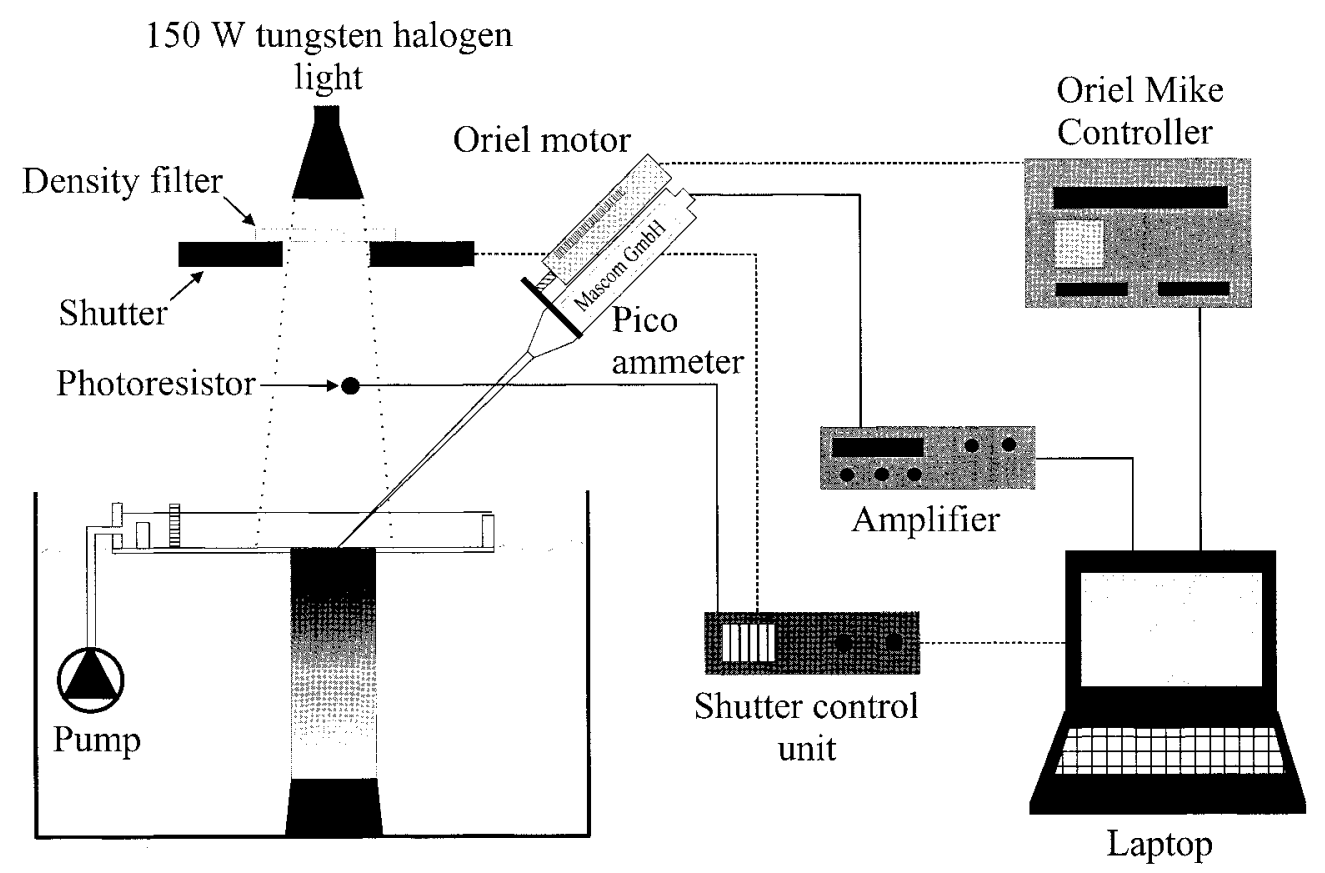

Fig. 1. Schematic presentation of the experimental setup.

Sample incubation-Samples were incubated in a flow chamber (Lorenzen et al. 1995), modified to allow the incubation of a complete sediment core (Fig. 1). The sediment was pushed up gently to the rim of the liner, and the core was inserted from below through the bottom of the flow chamber. In this way, the mat surface was flush with the upper surface of the bottom plate of the flow chamber. The chamber with core was placed in an aquarium with filtered water from the sampling site, which was continuously sparged with air and thermostated at $21 \pm 0.2^{\circ} \mathrm{C}$. A laminar waterflow in the chamber was created by feeding the inflowing water through a perforated wall upstream of the sample. The mat was illuminated from above by a $150 \mathrm{~W}$ fiber-optic tungsten-halogen light (Schott KL 1500) with neutral density filters (Oriel) inserted in the light path to reduce the incident irradiance. The surface irradiance at the mat surface was measured by a LiCor quantum sensor. A computer-controlled, high-speed electronic shutter (Vincent Ass. type VS35S2T0) was positioned in the light path to manipulate the light exposure of the mat. A photoresistor with a time characteristic of $<20 \mathrm{~ms}$ between the shutter and the mat recorded the actual light status of the mat.

pH measurements- $\mathrm{pH}$ profiles were recorded with liquid ion exchange (LIX) microelectrodes having a tip diameter of $4 \mu \mathrm{m}$. The capillaries were constructed and shielded as described by Jensen et al. (1993). The capillaries were backfilled with a filtered electrolyte (Acrodisc $0.2 \mu \mathrm{m}$ ) containing $0.3 \mathrm{M} \mathrm{KCl}$ and $0.05 \mathrm{M} \mathrm{Na}_{2} \mathrm{HPO}_{4}$ adjusted to $\mathrm{pH} 7.0$ by $\mathrm{HCl}$. Under microscopic observation, a LIX cocktail containing $6 \%(\mathrm{w} / \mathrm{w})$ 4-nonadecylpyridine $\left(\mathrm{H}^{+}\right.$-ionophore $\left.\mathrm{II}\right)$ and $1 \%$ $(\mathrm{w} / \mathrm{w})$ potassium-tetrakis (4-chlorophenyl) borate in 2-nitrophenyl-octyl-ether was introduced through the tip by underpressure, provided by a syringe connected to the shaft of the electrode. All chemicals were purchased from Fluka. The electrodes were calibrated by measuring the electron motive force (emf) versus a standard calomel electrode in conventional National Bureau of Standards buffer solutions. The typical emf was $55 \mathrm{mV} \mathrm{pH}^{-1}$, and $90 \%$ response times were between 0.5 and $3 \mathrm{~s}$.

Oxygen measurements-Oxygen concentrations were measured with a Clark type oxygen microsensor equipped with an internal guard electrode (Revsbech 1989). This custom-built sensor had a tip diameter of $7 \mu \mathrm{m}$, a stirring sensitivity of $<1.5 \%$, and a $90 \%$ response time of $0.2 \mathrm{~s}$. The linearity of the sensor response was confirmed by recording the output current in water sparged with $\mathrm{N}_{2}$, air, and pure $\mathrm{O}_{2}$, respectively. The sensor was calibrated at the experimental temperature, using the output current in the overlying water and in the anoxic mat for air saturation and zero oxygen, respectively. The output current, measured by a miniaturized picoampere meter mounted directly on the shaft of the microsensor (MasCom $\mathrm{GmbH}$, Germany), was converted to a millivolt signal, filtered at $50 \mathrm{~Hz}$ to minimize electrical noise, and digitized by an A/D converter (AT-MIO-16XE50, National Instruments) for PC data acquisition.

The sensor entered the mat under an angle of $45^{\circ}$ (sensor tip in upstream direction) by a motor-driven micromanipulator (L.O.T. Oriel, Märzhäuser). A dissection microscope was used to position the tip of the sensor at the mat surface, which served as the reference depth for vertical positioning. The positioning of the microsensor, light-dark-light transitions by closing or opening the shutter, data acquisition, and statistical analysis of the sensor output were all done automatically by custom-made hardware and software routines (Labview, National Instruments). 
Gross photosynthesis measurements-The rates of oxygenic gross photosynthesis were determined at $100-\mu \mathrm{m}$ intervals by applying the microsensor light-dark shift method (Revsbech et al. 1981; Revsbech and Jørgensen 1983). Upon reaching a steady state distribution of oxygen at $180 \mu \mathrm{mol}$ photons $\mathrm{m}^{-2} \mathrm{~s}^{-1}$, the microsensor was positioned at depth $z$ ( $\pm 3 \mu \mathrm{m}$ ), and the mat was darkened for 0.5 to $1.5 \mathrm{~s}$ by closing the high-speed electronic shutter. The actual start of the dark period was recorded by a photoresistor positioned in the light path between the shutter and the mat. The sensor output was sampled at a frequency of $1,000 \mathrm{~Hz}$ starting $2 \mathrm{~s}$ prior to the dark period to verify a steady state signal before the actual rate measurement. The initial decrease in oxygen concentration was estimated by linear regression, using a least-square analysis procedure. The rate of oxygenic gross photosynthesis at depth $z$ should equal the initial rate of oxygen decrease during darkening by assuming that the rates of oxygen consumption were identical before and during darkening and that the diffusive transport of oxygen at this depth is constant during the procedure (Glud et al. 1992). The measurements yield photosynthetic activities per volume of pore water, expressed here in units of $\mathrm{nmol} \mathrm{O}_{2} \mathrm{~cm}^{-3}$ (pore water) $\min ^{-1}$.

\section{Light-dark cycles}

Theory-The distribution of oxygen in a mat is governed by the production or consumption of oxygen and the diffusive transport of oxygen. By considering the microbial mat as an infinite flat plate without lateral variation and assuming a uniform depth distribution of porosity, $\phi$, and of the sediment diffusion coefficient, $D_{s}$, the oxygen concentration as a function of time $t$ and depth $z, C(z, t)$, can be expressed mathematically by the general diffusion-reaction equation

$$
\frac{\partial C(z, t)}{\partial t}=D_{s} \frac{\partial^{2} C(z, t)}{\partial z^{2}}+\underbrace{P(z, t)-R(z, t),}_{A(z, t)}
$$

or, after rearranging,

$$
A(z, t)=\frac{\partial C(z, t)}{\partial t}-D_{s} \frac{\partial^{2} C(z, t)}{\partial z^{2}} .
$$

$A(z, t)$ represents the net rate of reactions that affect the concentration of oxygen, where $P(z, t)$ and $R(z, t)$ represent the rate of oxygenic photosynthesis and the rate of oxygen consumption by respiratory and chemical oxidation processes at depth $z$ at time $t$, respectively.

After prolonged exposure to a constant irradiance, the distribution of oxygen concentration attains a steady state, i.e., the distribution of the oxygen concentration is time independent, $[\partial C(z, t)] / \partial t=0$. For any given depth, the diffusive exchange of oxygen is balanced now by photosynthetic production and oxygen consumption. Upon darkening, the photosynthetic oxygen production halts instantaneously, and the former steady state profile of oxygen concentration will change as a consequence of ongoing diffusion and oxygen consumption. Now, $A(z, t)$ in Eq. 1 only represents the oxygen consuming processes. Thus, the rate of oxygen consumption as a function of depth and time can be calculated from the second derivative of the oxygen concentration as a function of depth and the rate of change in oxygen concentration upon perturbing the stationary condition attained during illumination through darkening. Incubation in darkness eventually results in a new stationary condition, in which the rate of oxygen consumption is balanced by the diffusive exchange of oxygen.

Switching on the light invokes oxygenic photosynthesis, which results in a perturbation of the dark stationary condition. $A(z, t)$ in Eq. 1 now represents $P(z, t)-R(z, t)$, previously defined as the net oxygen metabolism. Analogous to the calculation of oxygen consumption, net oxygen metabolism can be calculated from the oxygen concentrations as a function of depth and time after exposure to light. This sequence of events forms the basis of the light-dark cycle procedure as applied in this study.

Data acquisition procedure-The following procedure was designed to acquire the concentration of oxygen as a function of depth and time after a change in light status (dark or light). After attaining a steady state distribution of oxygen at a surface irradiance of $180 \mu \mathrm{mol}$ photons $\mathrm{m}^{-2} \mathrm{~s}^{-1}$, the oxygen sensor was positioned at $0.1 \mathrm{~cm}$ above the mat-water interface. The system was allowed to equilibrate for $1 \mathrm{~s}$ before the shutter was closed, leaving the mat in darkness. Immediately after darkening, the concentration of oxygen was recorded for $1 \mathrm{~s}$ at a sampling frequency of $510 \mathrm{~Hz}$, averaged, and stored. Subsequently, every $5 \mathrm{~s}$ the output was sampled for $1 \mathrm{~s}$, averaged, and stored for the appropriate time after darkening. After a total incubation time of $30 \mathrm{~min}$ in darkness, the shutter was opened, exposing the mat to light. An identical data acquisition procedure was followed for the light period. After $30 \mathrm{~min}$ of exposure to light, the electrode moved down $100 \mu \mathrm{m}$ and the system was allowed to equilibrate for $1 \mathrm{~s}$ again before closing the shutter and acquiring data. This procedure was repeated until the electrode reached a depth of $0.2 \mathrm{~cm}$, thereby exceeding the maximum penetration depth of oxygen during light exposure. This procedure is referred to as the (light-dark) cycling method, to distinguish it from the light-dark shift method for measurement of gross photosynthesis.

Numerical simulation-In the numerical computations reported here, we calculate $A$ from Eq. 1 using known concentration profiles by the following procedure. An initial profile of $c_{m}(t=0, z)$ (subscript $m$ refers to measurements) is taken, and a concentration profile after one time step $c_{d}(t$ $=\Delta t, z$ ) (subscript $d$ refers to pure diffusion) is calculated, using a pure diffusion equation (i.e., Eq. 1 without $A(z, t)$ ). Obviously, the difference $c_{m}(t=\Delta t, z)-c_{d}(t=\Delta t, z)$ can be attributed to the action of the activity $A$. In a likewise manner $A$ is calculated for later times. The solution technique for Eq. 1 is based on the Crank-Nicholson method (Crank and Nicholson 1947), after Eq. 1 is discretized by finite differences. A standard solution algorithm of the numerical routines (Press et al. 1992) was chosen to obtain the solution of the linear algebraic equation. The solution of Eq. 1 has to be determined using appropriate initial and boundary conditions on concentration $c(z, t)$. 


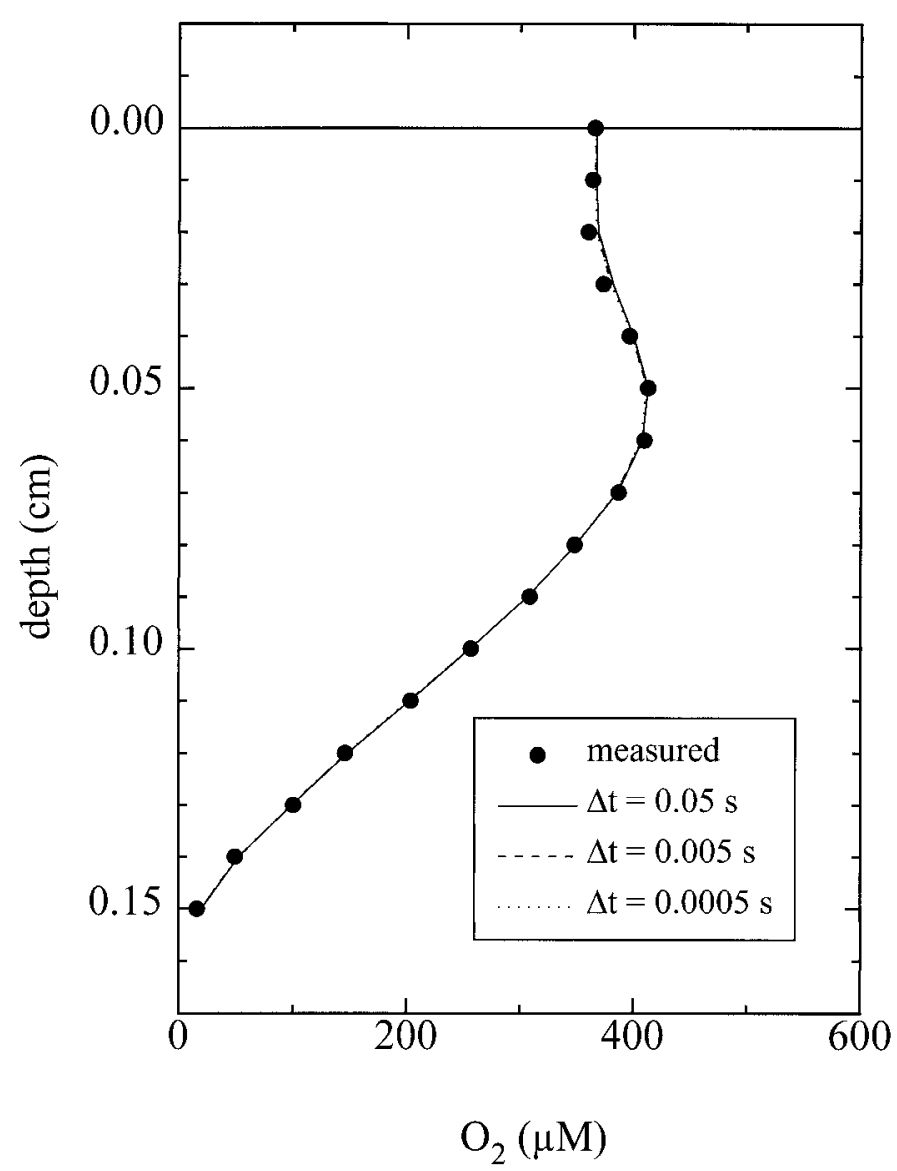

Fig. 2. Comparison between the numerical solutions at three different time resolutions and the experimental data (circles).

Initial and boundary conditions-As an appropriate initial condition, $c\left(t=t_{0}, z\right)=c_{m}\left(t_{0}, z\right)$ was taken. Boundary conditions have to be formulated at the sediment-water interface, $z=0$ and $z=z_{\max }$. The sediment-water interface is assumed to be a horizontal plane. At the interface, the conservation of flux leads to

$$
-D_{0} \frac{\partial c\left(t, z=0^{-}\right)}{\partial z}=-\phi D_{s} \frac{\partial c\left(t, z=0^{+}\right)}{\partial z}
$$

with $0^{-}$and $0^{+}$denoting the overlying water and pore water, respectively. Equal flux condition at the interface is an appropriate condition provided a good estimate of porosity $\phi$ is available; otherwise, the continuity of mass will not be satisfied.

Finally, the no-flux condition at $z=z_{\max }$ leads to

$$
\frac{\partial c\left(t, z=z_{\max }\right)}{\partial z}=0
$$

Calculation of steady state fluxes-Steady state fluxes of oxygen across the mat-water interface were calculated according to Fick's first law of diffusion:

$$
J_{0}=-D_{0} \frac{d C}{d z}
$$

where $D_{0}$ represents the free solution molecular diffusion coefficient of oxygen in water, which amounts to $2.11 \times$ $10^{-5} \mathrm{~cm}^{2} \mathrm{~s}^{-1}$ at $21^{\circ} \mathrm{C}$ and a salinity of 15.4 (Broecker and Peng 1974; Li and Gregory 1974). The concentration gradient, $d C / d z$, was estimated from the linear part of the oxygen gradient nearest to the mat-water interface. Depth, $z$, was scaled zero at the sediment-water interface, positive in the downward direction. As a consequence, fluxes in the downward direction are scaled positive. For the calculation of fluxes within the mat, the molecular diffusion coefficient was replaced by the diffusivity, $\phi D_{s}$.

Porosity and diffusion coefficient-Since microbial mats consist mainly of cytosol containing cells embedded in a polymer matrix with a minor admixture of lithogenic material, conventional drying techniques may not result in a good estimate of porosity. Therefore, mat porosity was estimated by assuming the conservation of oxygen flux across the matwater interface. Rearranging the equality of fluxes through the diffusive boundary layer (DBL) and the top layer of the sediment yields the following expression for porosity:

$$
\phi=\frac{D_{0}\left(\frac{d C}{d z}\right)_{D B L}}{D_{s}\left(\frac{d C}{d z}\right) m a t} .
$$

The diffusion coefficients are eliminated by substitution of

$$
\frac{D_{s}}{D_{0}}=\frac{1}{1+n(1-\phi)},
$$

using a value of 3 for $n$ as suggested by Iversen and Jørgensen (1992). It should be noted that the concentration gradients in Eq. 4 are to be taken from the steady state profiles (see Rasmussen and Jørgensen 1992). This approach yields a porosity of 0.95 to 0.97 at the mat-water interface. Owing to compaction and the inclusion of lithogenic material, this high surface value may overestimate porosity at depth. Therefore, a somewhat lower porosity of 0.9 was adopted, which was assumed to be depth invariant.

The contribution of the diffusion term in the calculation of activity (see Eq. 1) is directly proportional to the value of the sediment diffusion coefficient, $D_{s}$. The diffusion coefficients in this study were calculated from the diffusivities $\left(\phi D_{s}\right)$ as presented by Glud et al. (1995) for a biologically active microbial mat as measured by nitrous oxide sensors. The average value of $\phi D_{s}$ at $20^{\circ} \mathrm{C}$ was $1.41 \times 10^{-5} \mathrm{~cm}^{2} \mathrm{~s}^{-1}$, with a minimum and maximum value of $1.15 \times 10^{-5} \mathrm{~cm}^{2}$ $\mathrm{s}^{-1}$ and $1.74 \times 10^{-5} \mathrm{~cm}^{2} \mathrm{~s}^{-1}$, respectively. These values are based on the assumption of identical diffusion coefficients for oxygen and nitrous oxide (Broecker and Peng 1974), although other studies have presented differences of up to $18 \%$ (e.g., Wanninkhof 1992). The diffusivity was assumed to be constant with depth over the entire oxic layer of the mat (Revsbech et al. 1986; Glud et al. 1995). Although the activity calculations were performed with all three values, only the results from the average value are graphically presented. 


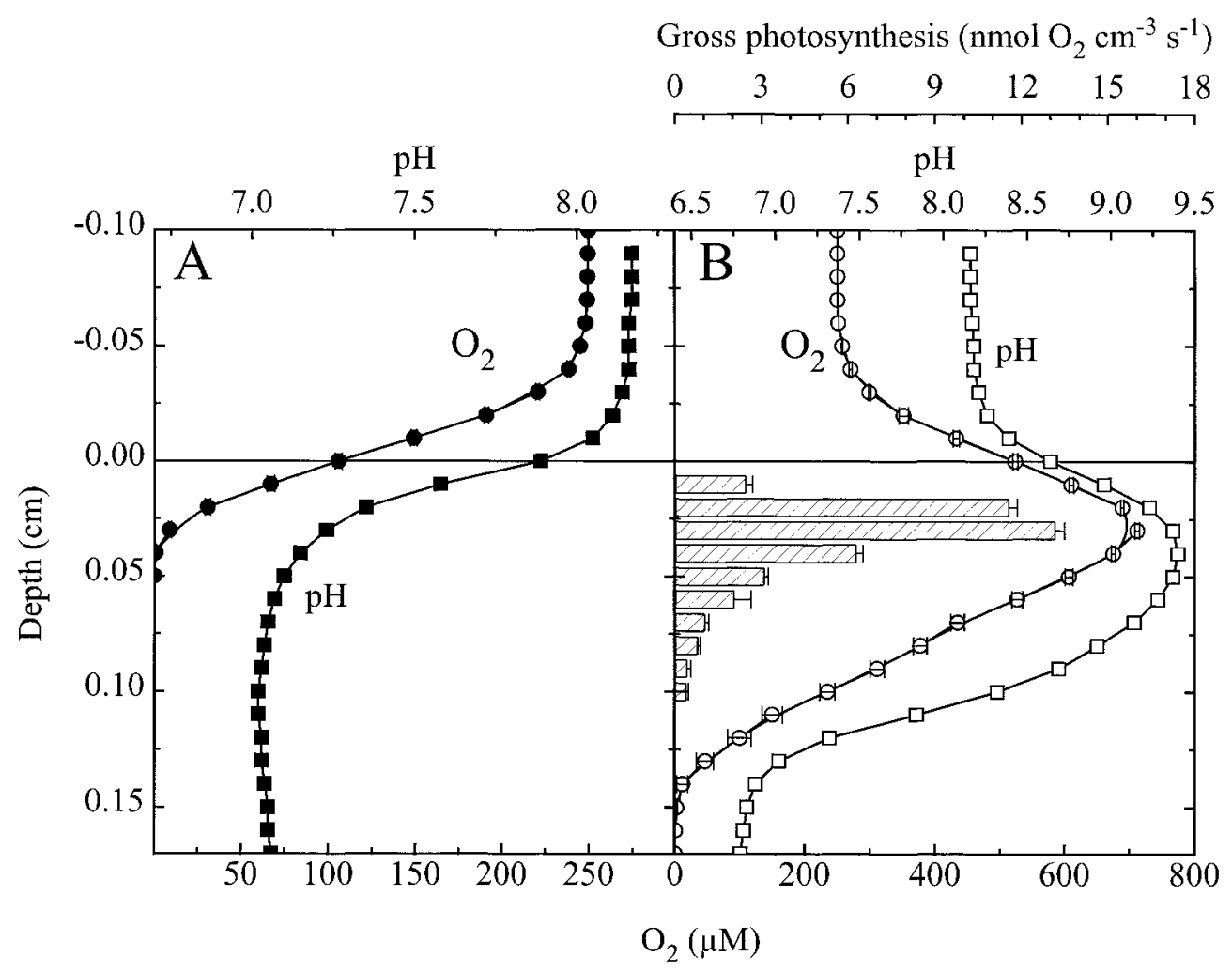

Fig. 3. Average steady state profiles of oxygen (circles, $n=4)$, $\mathrm{pH}$ (squares), and gross photosynthesis (bars, $n=6-10$ ) in an intertidal microbial mat incubated in darkness (A) and at a surface irradiance of $180 \mu \mathrm{mol}$ photons $\mathrm{m}^{-2} \mathrm{~s}^{-1}(\mathrm{~B})$. The error bars indicate \pm 1 standard deviation.

Results

Numerical accuracy-In order to obtain convergent solutions, different time resolutions were investigated and are presented in Fig. 2. Four different time-resolution refinements $(\Delta t=0.05,0.005,0.0005$, and 0.00005$)$ were taken, and the results were compared with the experimental oxygen measurements for which the time step $\Delta t$ was $5 \mathrm{~s}$. As can be seen in the figure, the comparison between the experimental values and the numerical simulation is good, and a time step of $\Delta t=0.005$ seconds is sufficient. All presented calculations, though, were performed using a time step of $\Delta t$ $=0.00005 \mathrm{~s}$ to fulfill all stability requirements. The stability of the results is assured by satisfying John's stability condition (Richtmyer and Morton 1967), which requires a time: space resolution ratio of $0<\lambda=\left(\Delta t / \Delta z^{2}\right)<0.5$.

Steady state measurements-Prior to the cycling experiment, steady state profiles of oxygen were measured for a range of surface irradiances. The saturation value, $E_{k}$, for net oxygenic photosynthesis was estimated from a plot of net oxygenic photosynthesis against surface irradiance and amounted to $180 \mu \mathrm{mol}$ photons $\mathrm{m}^{-2} \mathrm{~s}^{-1}$. The steady state profiles of oxygen and $\mathrm{pH}$ for darkness and for $180 \mu \mathrm{mol}$ photons $\mathrm{m}^{-2} \mathrm{~s}^{-1}$ are presented in Fig. 3. As a consequence of the higher diffusion coefficient of protons $\left(8.5 \times 10^{-5}\right.$ $\mathrm{cm}^{2} \mathrm{~s}^{-1}$ ) relative to oxygen, a thicker diffusive boundary layer is expected for protons as compared to oxygen. How- ever, the estimated thickness of the effective diffusive boundary layer was $0.03 \mathrm{~cm}$ for $\mathrm{O}_{2}$ and $0.025 \mathrm{~cm}$ for protons for both conditions. This difference may result from small topographical differences in the mat surface, resulting in lateral variability in thickness of the diffusive boundary layer, and from the difficulty to assign the exact position of the mat-water interface. In darkness, the oxic layer was restricted to the upper $0.05 \mathrm{~cm}$ of the mat. The $\mathrm{pH}$ decreased from 8.15 in the overlying water to ca. 7.0 at the oxic-anoxic interface, presumably due to the production of carbon dioxide from oxic carbon mineralization and the liberation of protons during the reoxidation of reduced compounds (e.g., nitrification). $\mathrm{H}_{2} \mathrm{~S}$ could not be detected in this layer, and its reoxidation probably did not contribute to oxygen consumption and lowering in $\mathrm{pH}$. Incubation of the mat at a surface irradiance of $180 \mu \mathrm{mol}$ photons $\mathrm{m}^{-2} \mathrm{~s}^{-1}$ resulted in a subsurface maximum in oxygen concentration, giving rise to an expansion of the oxic layer to $0.16 \mathrm{~cm}$ (Fig. 3B). The rates of gross oxygenic photosynthesis, as measured by the lightdark shift technique, were nil at the mat-water interface, increased to a maximum of $13.1 \mathrm{nmol} \mathrm{cm}{ }^{-3} \mathrm{~s}^{-1}$ for the depth interval of 0.025 to $0.035 \mathrm{~cm}$, and subsequently declined exponentially with depth. The depth of the euphotic layer, defined as the maximum depth that allowed for detectable rates of photosynthesis, was $0.1 \mathrm{~cm}$. In the euphotic layer the $\mathrm{pH}$ increased to a maximum value of ca. 9.4 as a consequence of $\mathrm{HCO}_{3}^{-}$uptake and the subsequent release of $\mathrm{OH}^{-}$during benthic photosynthesis. The $\mathrm{pH}$ decreased steep- 
Time (s)

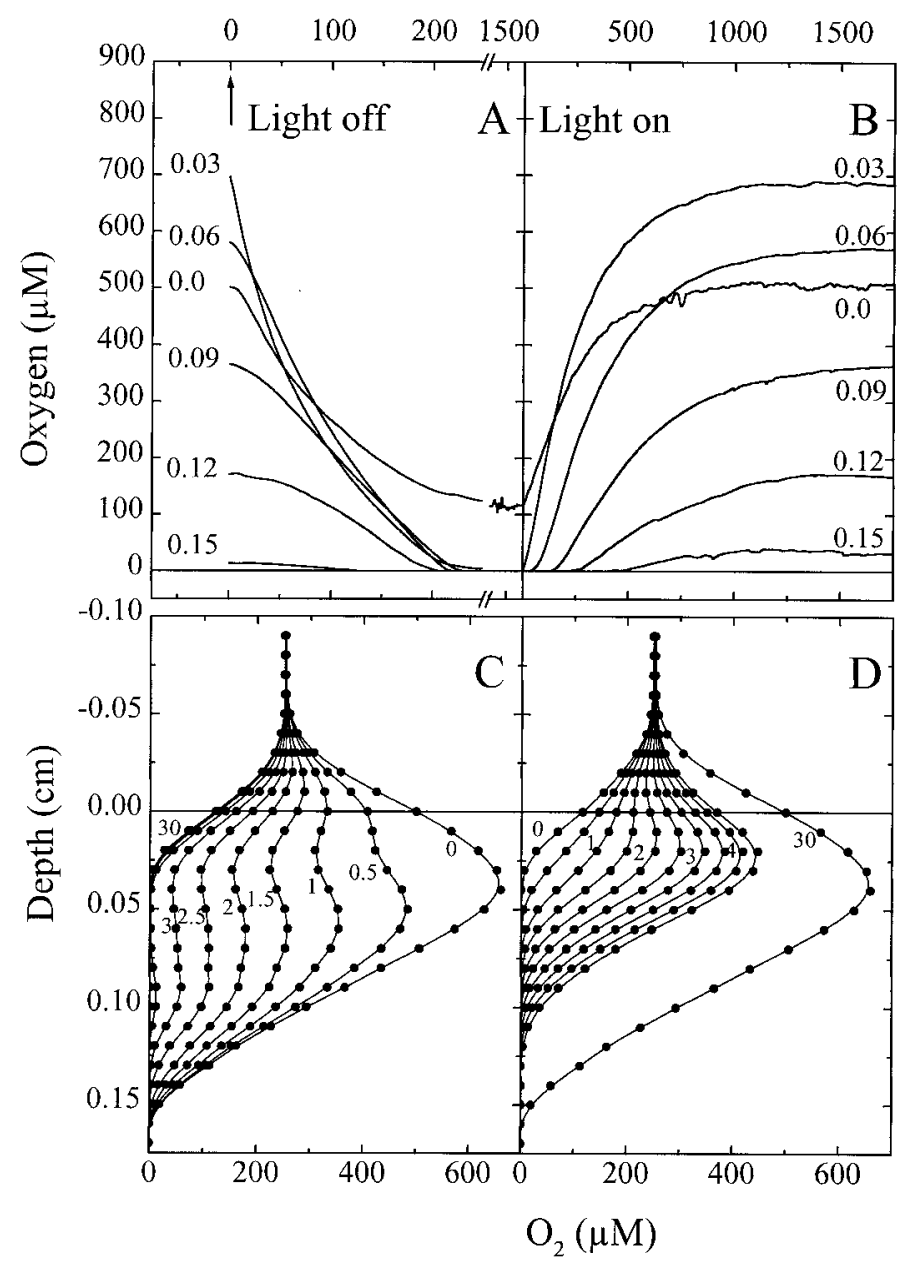

Fig. 4. Oxygen concentrations in a microbial mat as a function of time and depth after darkening $(\mathrm{A}, \mathrm{C})$ and after the start of illumination at a surface irradiance of $180 \mu \mathrm{mol}$ photons $\mathrm{m}^{-2} \mathrm{~s}^{-1}$ (B, D). Panels A and B present a selection of the complete data set as concentration-time curves for defined depths. The numbers on the curves correspond to depth in the mat $(\mathrm{cm})$. Note the axis break in panel A. Panels C and D present a selection of data as concentration-depth profiles in the mat for defined times (min) after darkening or start of illumination, as indicated by the numbers on the profiles.

ly below this layer to an asymptotic value of 6.7 due to mineralization and reoxidation reactions associated with the consumption of oxygen.

\section{Light-dark cycling}

The dark period-Figure 4A shows the measured concentrations of oxygen for a number of depths as a function of time after darkening. Upon darkening, a new steady state condition was attained in $\sim 200 \mathrm{~s}$, as indicated by the minor changes in oxygen concentration for any depth beyond this time coordinate. Alternatively, the data can be presented as transient oxygen profiles, which are obtained by plotting the oxygen concentrations versus depth for a defined time after darkening. A selection of reconstructed profiles following the extinction of light are shown in Fig. 4C. The transient oxygen profiles after darkening were used to calculate the rates of oxygen consumption as a function of depth and time according to Eq. 1. A selection of the results is presented in Fig. 5 as the distribution of oxygen consumption rates versus depth for different time coordinates after darkening. Immediately after darkening, the rate of oxygen consumption was $3 \mathrm{nmol} \mathrm{O}_{2} \mathrm{~cm}^{-3} \mathrm{~s}^{-1}$ at the mat-water interface, increased with depth to a maximum rate of $7 \mathrm{nmol} \mathrm{O}_{2} \mathrm{~cm}^{-3} \mathrm{~s}^{-1}$ at 0.02 $\mathrm{cm}$, and subsequently showed a decrease with depth to a value of $1 \mathrm{nmol} \mathrm{O}_{2} \mathrm{~cm}^{-3} \mathrm{~s}^{-1}$ at $0.05 \mathrm{~cm}$. In the 0.05 to 0.12 $\mathrm{cm}$ stratum, the oxygen consumption rate was evenly distributed with depth at a rate of 1 to $1.5 \mathrm{nmol} \mathrm{O}_{2} \mathrm{~cm}^{-3} \mathrm{~s}^{-1}$. Below this intermediate layer, the rates of oxygen consumption increased to ca. $3 \mathrm{nmol} \mathrm{O}_{2} \mathrm{~cm}^{-3} \mathrm{~s}^{-1}$, which may be attributed to the reoxidation of reduced compounds, generated during the anoxic mineralization of organic carbon. With time, the activity in the 0 to $0.05 \mathrm{~cm}$ layer decreased, resulting in a steady state maximum activity at $0.02 \mathrm{~cm}$ of $2.5 \mathrm{nmol} \mathrm{O} \mathrm{cm}^{-3} \mathrm{~s}^{-1}$. The activity in the depth horizon 0.05 to $0.08 \mathrm{~cm}$ showed an increase until 3 min after darkening, and a subsequent decrease when the availability of oxygen apparently limited the consumption activity. The second consumption maximum, initially observed at $0.15 \mathrm{~cm}$ depth, migrated upward with time to $0.12 \mathrm{~cm}$ depth at $3 \mathrm{~min}$ after darkening, before dissipating as a consequence of oxygen limitation.

Figure 6 shows the oxygen consumption activities for some representative depths as a function of time. The rate of oxygen consumption in the upper 0 to $0.05 \mathrm{~cm}$ layer, represented by 0.01 and $0.02 \mathrm{~cm}$ in Fig. 6A, decreased with time, starting immediately after the onset of darkness, finally stabilizing at $<50 \%$ of the initial values. The consumption rate in the 0.05 to $0.08 \mathrm{~cm}$ layer (deeper stratum of the formerly photic layer), represented by $0.06 \mathrm{~cm}$, increased with time after darkening, stabilized after ca. $150 \mathrm{~s}$, and decreased after $200 \mathrm{~s}$, presumably as the consequence of oxygen limitation. The oxygen consumption activities in the deeper part of the oxic layer showed clear trends with time as well (Fig. 6B). The activity at $0.13 \mathrm{~cm}$, initially at the boundary between the intermediate zone and the secondary activity maximum (cf. Fig. 5), increased with time after darkening, showing a maximum at ca. $150 \mathrm{~s}$, and subsequently decreased as oxygen became limiting. At $0.11 \mathrm{~cm}$ depth, the activity decreased upon darkening, but increased after ca. $150 \mathrm{~s}$, showing a maximum after $195 \mathrm{~s}$ before the onset of oxygen limitation. At $0.09 \mathrm{~cm}$ the activity showed a similar trend; however, the peak in activity was even more delayed as compared to the deeper layers and occurred at $220 \mathrm{~s}$ after darkening. In addition, the peak value in oxygen consumption rate decreased with shallower depth. These activity-time plots suggest that the oxygen consumption activity is controlled by the supply of both oxygen and oxidizable substrates.

Plotting the rates of oxygen consumption against the oxygen concentrations for a given depth reveals a hyperbolic relation between activity and the concentration of oxygen. The consumption activities calculated for oxygen concentrations up to $50 \mu \mathrm{M}$ are shown for a number of depths in Fig. 


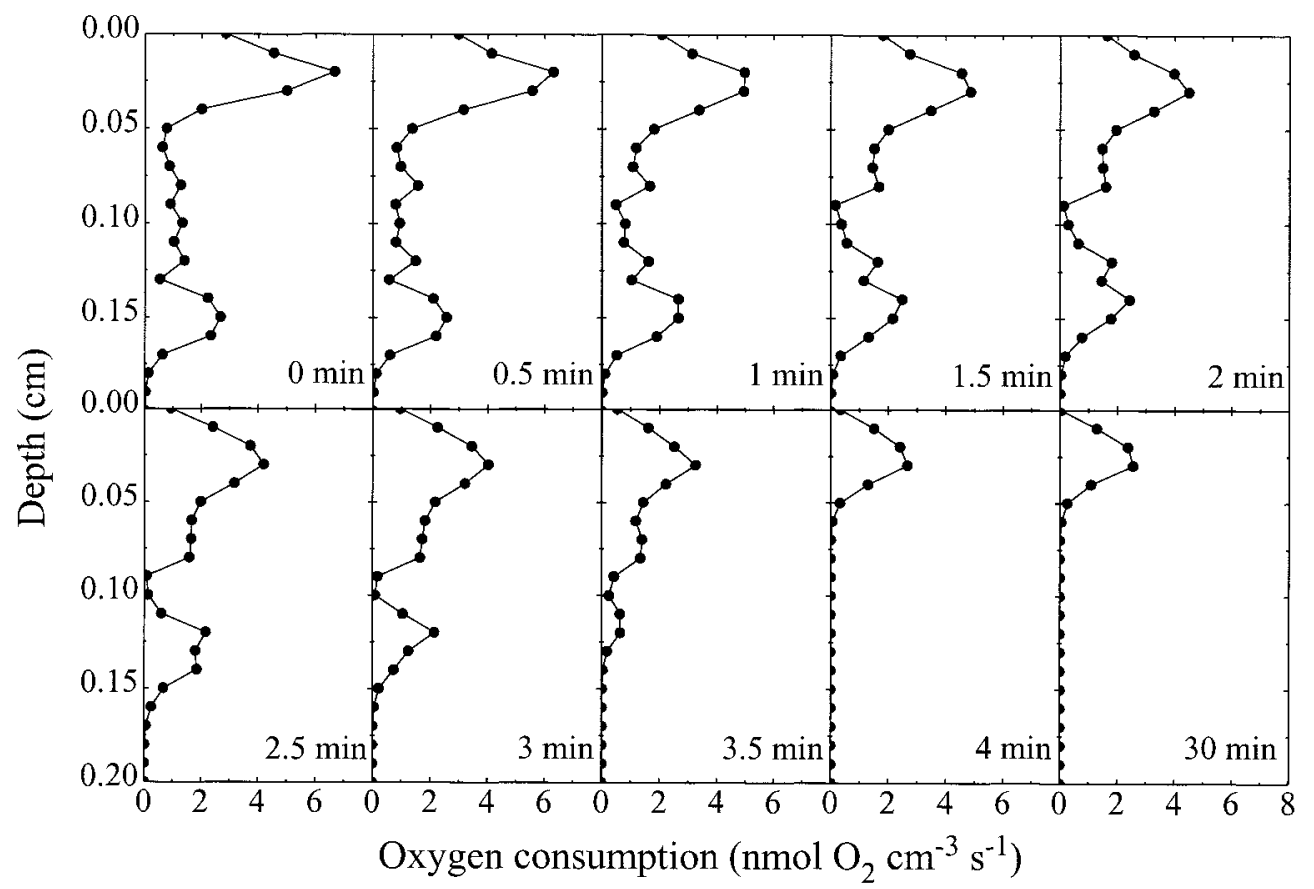

Fig. 5. Oxygen consumption profiles in a microbial mat at 0.5 min intervals after darkening. A new steady state distribution of oxygen consumption is attained after ca. 4 min in darkness. The activities were calculated from the oxygen concentration as a function of time and depth, as presented in Fig. 4A and 4C.

7. The data were fitted to the Michaelis-Menten equation (Levenberg-Marquardt algorithm, Microcal Origin) to estimate the apparent affinity constant for oxygen, $k_{m}^{\prime}$, and the maximum rate of oxygen consumption, $R_{\max }$, for different depths in the oxic layer. $R_{\max }$, which is a composite of chemical and biological oxidation activities, ranged from $5 \mathrm{nmol}$ $\mathrm{O}_{2} \mathrm{~cm}^{-3} \mathrm{~s}^{-1}$ at $0.02 \mathrm{~cm}$ to $2.1 \mathrm{nmol} \mathrm{O}_{2} \mathrm{~cm}^{-3} \mathrm{~s}^{-1}$ at $0.08 \mathrm{~cm}$ depth. The estimated apparent affinity constants ranged from 4.6 to $12 \mu \mathrm{M}$, without a clear distribution with depth.

The light period-After 30 min in darkness, the mat was exposed to a surface irradiance of $180 \mu \mathrm{mol}$ photons $\mathrm{m}^{-2}$ $\mathrm{s}^{-1}$, resulting in the concentration versus time curves as shown in Fig. 4B. The time required to attain steady state
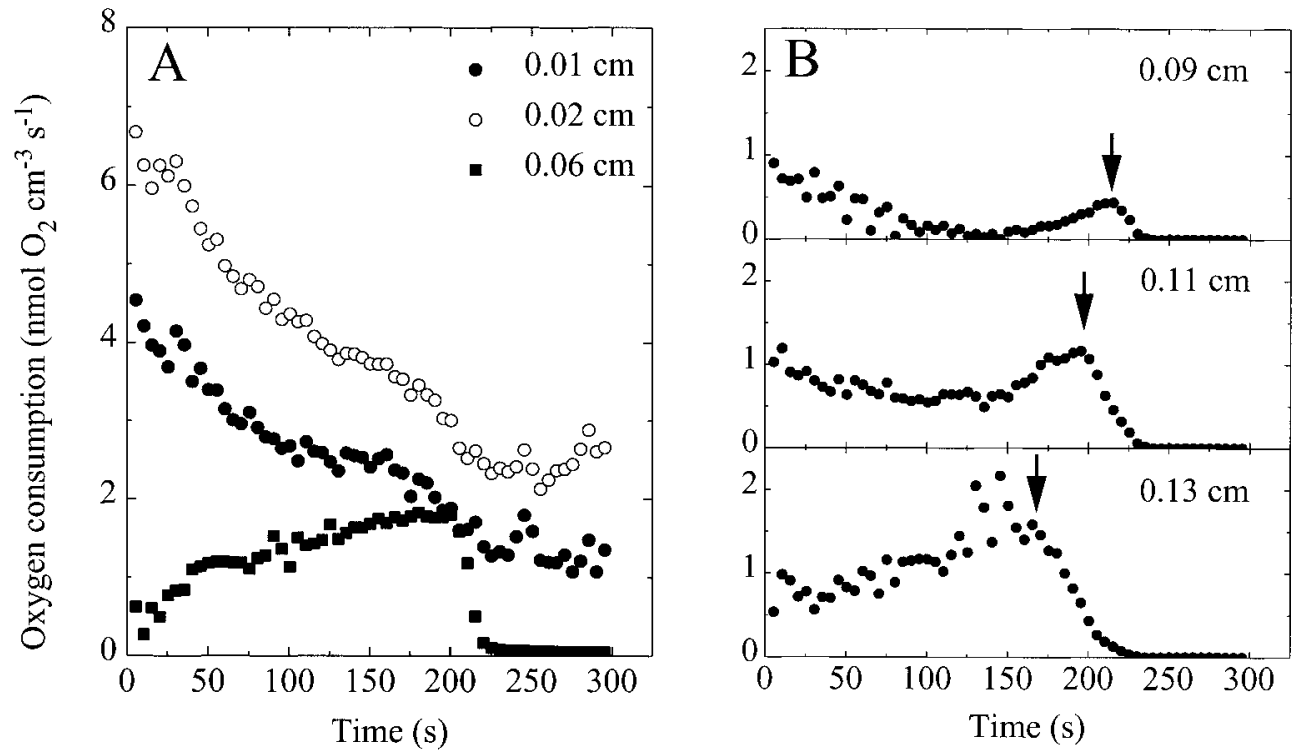

Fig. 6. Time courses of oxygen consumption rates after darkening for defined depths in the microbial mat. The arrows in panel $\mathrm{B}$ indicate the maximum oxygen consumption activity and the onset of oxygen limitation. 


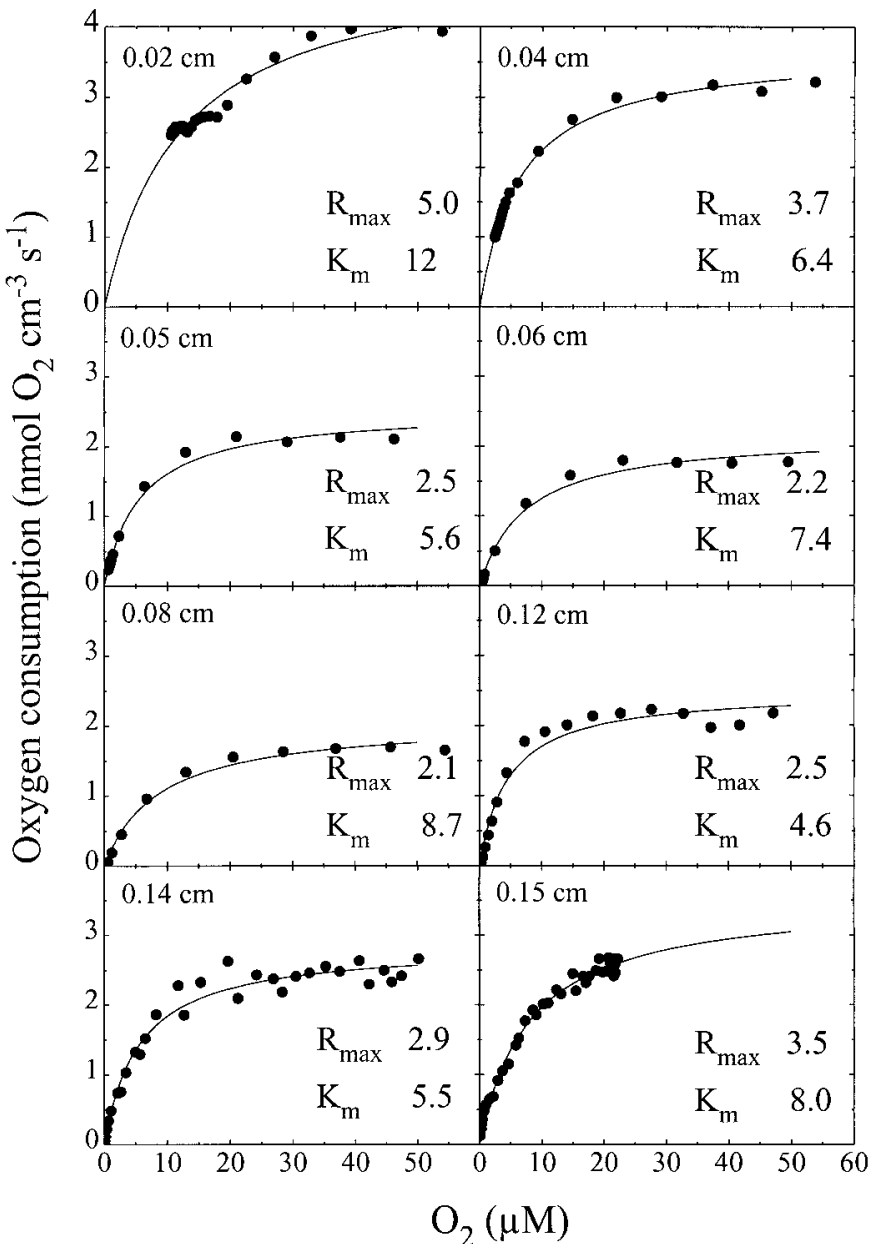

Fig. 7. Oxygen consumption activity against the oxygen concentration for several depths in the mat. The plots were constructed from the oxygen concentrations between 0 and $50 \mu \mathrm{M} \mathrm{O}$ and the corresponding oxygen consumption activities after darkening. Solid lines indicate the best fit of the Michaelis-Menten equation to the experimental data. The estimated values for the maximum oxygen consumption rate, $R_{\max }$, and apparent affinity constant for oxygen, $k_{m}^{\prime}$, are indicated in the plots.

conditions during illumination was considerably longer than the time for attaining a steady state in darkness and amounted to $\sim 1,000 \mathrm{~s}$. Figure 8 depicts the evolution of net oxygen metabolism (photosynthesis minus oxygen consumption) as a function of depth for the first $4.0 \mathrm{~min}$ after the start of illumination. Positive values indicate a net production, whereas negative values indicate a net consumption of oxygen. With time, the thickness of the layer that showed net production of oxygen increased from ca. $0.01 \mathrm{~cm}$ immediately after light exposure to $>0.06 \mathrm{~cm}$ after $4.0 \mathrm{~min}$. Concomitantly, the maximum value of net oxygen production increased from 1 to $6 \mathrm{nmol} \mathrm{O}_{2} \mathrm{~cm}^{-3} \mathrm{~s}^{-1}$. Apparently, the rates of oxygenic photosynthesis relative to oxygen consumption increased during this time span. Similar trends were observed for the layer that showed net consumption; the thickness expanded with time from 0.04 to $0.08 \mathrm{~cm}$, whereas the maximum activity steadily increased from 1 to
$2 \mathrm{nmol} \mathrm{O}_{2} \mathrm{~cm}^{-3} \mathrm{~s}^{-1}$ after $4.0 \mathrm{~min}$. Furthermore, the zone of net oxygen consumption moved downward with time.

Figure 9 shows time courses of net oxygen metabolism for several depths after the start of illumination. For $0.03 \mathrm{~cm}$ depth, representing the upper part of the photic layer, which remained oxic throughout the complete light-dark cycle, the net oxygen metabolism showed an immediate response. The onset of net oxygen metabolism in deeper layers, however, showed a delay, which increased with increasing depth. Since the oxic-anoxic interface moved downward with time after the start of illumination, this delay probably reflects the time required to oxygenate these depths. For all depths, the initial phase of net oxygen metabolism was dominated by oxygen consumption. With time, the net oxygen metabolism for a given depth decreased (i.e., oxygen consumption increased relative to photosynthesis) to a minimum. The timing of this minimum coincided with the onset of net oxygen metabolism in a successive deeper layer. At depths $<0.1 \mathrm{~cm}$ the minimum was followed by an increase in net oxygen metabolism, which eventually resulted in a net production of oxygen (positive values for net oxygen metabolism), while oxygen metabolism in deeper layers remained dominated by oxygen consumption.

After 25 min of light exposure, the oxygen concentration in the mat attained a steady state distribution, indicating that net oxygen metabolism at any depth was balanced by diffusive exchange. Figure 10A shows this steady state distribution for net oxygen metabolism in the photic layer of the mat, and the distribution of oxygen consumption, as obtained immediately after darkening. Summation of the net oxygen metabolism $(P-R)$ and oxygen consumption $(R)$ profiles yields an approximation of the distribution of gross photosynthesis briefly before darkening. This calculated distribution of gross photosynthesis revealed somewhat higher activities close to the mat-water interface and in the tail as compared to the photosynthesis profile as measured with the light-dark shift technique prior to cycling (cf. Fig. 3B). In contrast, the maximum values at 0.02 and $0.03 \mathrm{~cm}$ depth were slightly lower than the measured rates. The areal rates of gross photosynthesis were 24.9 and $29 \mathrm{nmol} \mathrm{O}_{2} \mathrm{~cm}^{-2}$ $\mathrm{min}^{-1}$ for the measured rates and calculated rates, respectively.

Since the exact value of $D_{s}$ for this mat is unknown, activity calculations have been performed with all three values: $1.28 \times 10^{-5}, 1.57 \times 10^{-5}$, and $1.93 \times 10^{-5} \mathrm{~cm}^{2} \mathrm{~s}^{-1}$. Figure $10 \mathrm{~B}$ shows the second-order derivative of oxygen concentration with respect to depth and the effect of the diffusion coefficient on the calculated rates of oxygen consumption at $60 \mathrm{~s}$ after darkening. When the second-order derivative attains a positive value, a relatively high oxygen consumption rate is associated with a high diffusion coefficient, whereas a relatively low rate is associated with a high diffusion coefficient when the second-order derivative attains a negative value.

\section{Discussion}

The first quantitative analysis of transient oxygen profiles (Revsbech et al. 1986) resulted in an oxygen consumption 


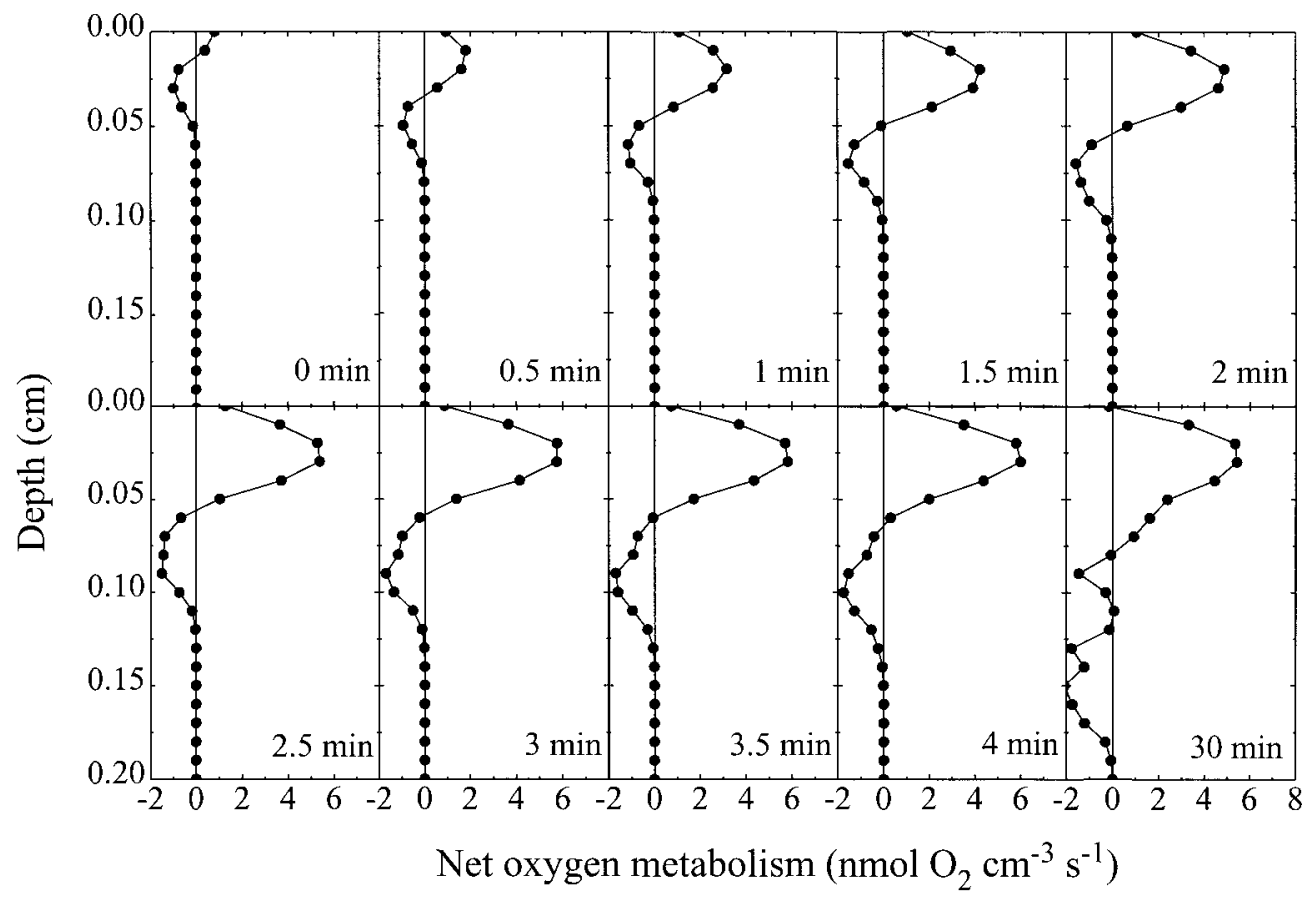

Fig. 8. Depth profiles of net oxygen metabolism (photosynthesis minus oxygen consumption) in a microbial mat at 0.5 -min intervals after the start of illumination at a surface irradiance of 180 $\mu \mathrm{mol}$ photons $\mathrm{m}^{-2} \mathrm{~s}^{-1}$. A new steady state distribution of net oxygen metabolism is attained only after ca. $25 \mathrm{~min}$ in light. The activities were calculated from the oxygen concentration as a function of time and depth, as presented in Fig. 4B and 4D.

profile similar to the profile as obtained immediately after darkening in the present experiment, i.e., enhanced oxygen consumption in the photic layer, an intermediate layer with relatively low activity, and increased activity close to the oxic-anoxic boundary. The previous study, though, did not present any dynamics in oxygen consumption activity. The time-dependent activity in the previous study was incorporated by the assumption that all rates of oxygen consumption would follow Michaelis-Menten kinetics with a $K_{m}$ value of $10 \mu \mathrm{M} \mathrm{O}_{2}$ to avoid numerical instabilities at low oxygen concentrations. Thus, the decrease in oxygen concentration with time would result in a decrease in the rate of oxygen consumption. In the present study, no such assumption was required, which allowed the apparent affinity constant for oxygen in different layers to be estimated from the calculated activities and the measured local oxygen concentrations. In addition, the present study indicates that the rates of oxygen consumption and of net oxygen metabolism in a specific layer are not merely controlled by oxygen availability, but probably by the supply of organic and inorganic substrates as well.

Oxygen consumption activities upon darkening-The depth distribution of oxygen consumption upon darkening showed elevated activities in the upper layer, reduced activities in the intermediate zone, and slightly enhanced rates at the oxic-anoxic interface. This oxygen consumption activity is a function of the oxygen concentration, of the concentration of oxidizable substrates, and, in the case of biological oxygen consumption, of the biomass involved. The affinity constants for oxygen as presented in the literature are generally in the lower micromolar range (e.g., Hao et al. 1983), suggesting that initially only the lower part of the oxygen consumption profile (where the oxygen concentration drops to zero) would be limited by the availability of oxygen. Thus, the remaining part of the oxygen consumption profile should be explained in terms of biomass distribution and the availability of oxidizable substrates. Plotting the activity for a specific depth against time after darkening rules out the effect of biomass, if it is assumed that the vertical distribution of oxygen consuming microorganisms does not change within the first 4 min after darkening. The resulting activitytime distributions thus show the effect of the changing chemical microenvironment (including the availability of oxidizable substrates) on the oxygen consumption activity.

A strong decrease in oxygen consumption activity with time is observed in the 0 to $0.03 \mathrm{~cm}$ layer, suggesting a decrease in the availability of substrates with time. Some chemical reoxidation reactions, such as the oxidation of reduced manganese and iron, are favored by high $\mathrm{pH}$ (Stumm and Lee 1961; Brewer 1975). A decrease in $\mathrm{pH}$ upon darkening could therefore result in a lowering of the oxygen consumption activity. However, it is unlikely that these reactions would dominate the oxygen consumption close to the mat-water interface shortly after the light period. More likely, the oxygen consumption in this layer is governed by the oxidation of newly fixed organic carbon (Falkowski et al. 1985). The oxygenase activity of the primary $\mathrm{CO}_{2}$ fixing enzyme ribulose bisphosphate carboxylase-oxygenase, RuBisco, is favored at conditions of low $\mathrm{CO}_{2} / \mathrm{O}_{2}$ ratios. 


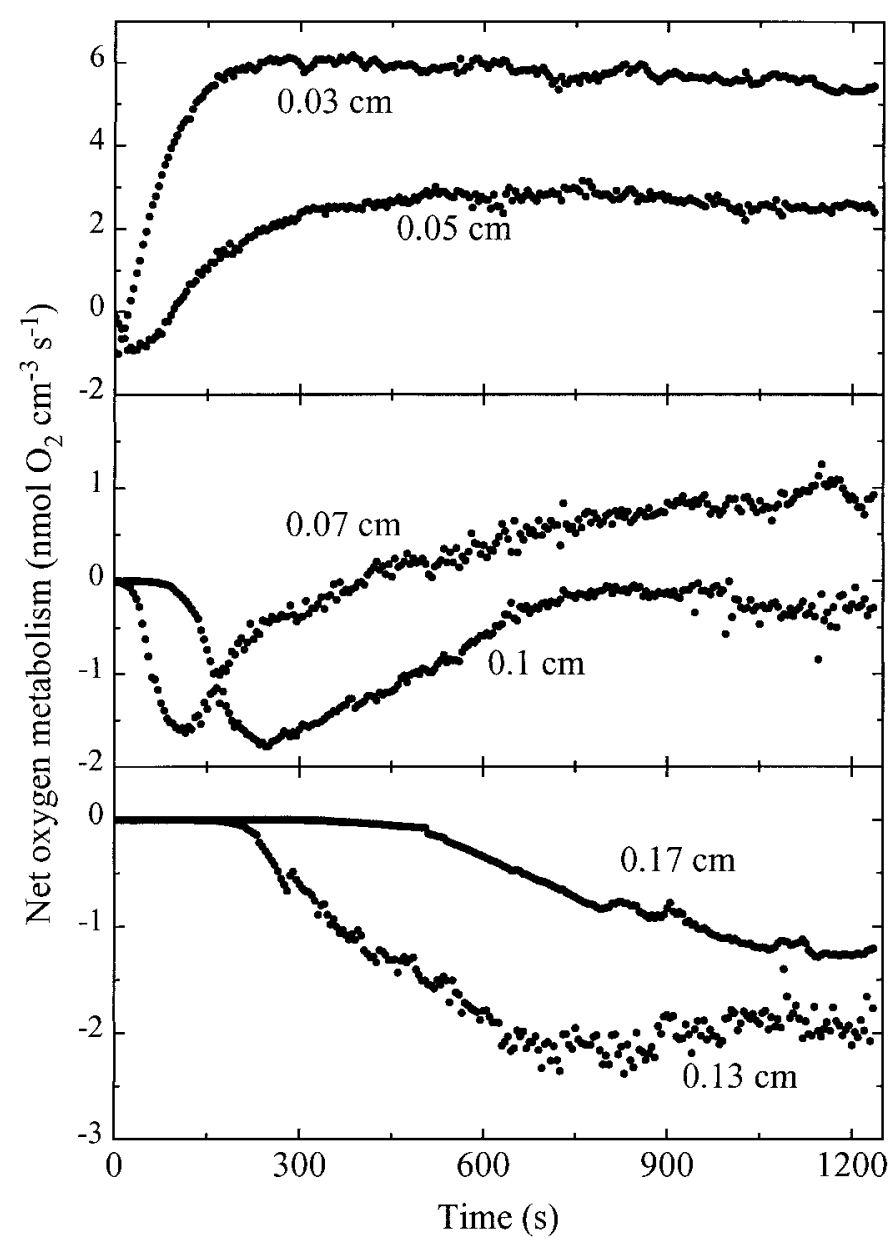

Fig. 9. Time courses of net oxygen metabolism after the start of illumination for different depths in the microbial mat. The depths are indicated on the curves.

These conditions may prevail during extended periods of illumination and may result in the oxidation of glycolate by the photorespiratory carbon-oxidation cycle (Beardall 1989) or in the exudation of glycolate and its subsequent oxidation by heterotrophic organisms (Han and Eley 1973; Bauld and Brock 1974; Bateson and Ward 1988; Baines and Pace 1991). The oxidation and diffusive losses of this easily degradable organic carbon pool may explain the decreasing rates of oxygen consumption with time in the upper $0.03 \mathrm{~cm}$ of the mat.

The reason for the increase in activity over time in the 0.05 to $0.08 \mathrm{~cm}$ layer is less obvious. The oxygen consumption activity in these layers can be adequately described in terms of oxygen affinity and oxygen inhibition, predicting full inhibition at a concentration of ca. $600 \mu \mathrm{M} \mathrm{O}_{2}$ (data not shown). However, it is not likely that the oxygen concentration itself inhibited the initial activity in this layer, since inhibition was absent in the upper 0 to $0.03 \mathrm{~cm}$ layer where even higher oxygen concentrations were measured. Similar arguments hold for the $\mathrm{pH}$ in this layer. Neither an enhanced downward flux of organic substrates upon darkening nor the upward flux of reduced compounds from below in this early phase after darkening are likely to explain the enhancement in oxygen consumption with time. It is therefore speculated that this increase in oxygen consumption might reflect the adaptation of a phototrophic population to respiratory conditions. The apparent consequence of this increase in oxygen consumption activity in the 0.05 to $0.08 \mathrm{~cm}$ layer is that the deeper layers become limited in the supply of organic substrates from the uppermost layer, initially resulting in a decrease in activity upon darkening (cf. Fig. 6B). The upward migration of the oxic-anoxic interface, though, results in a stronger supply of reductants to successively shallower layers with time from below, giving rise to enhanced rates of oxygen consumption. This stimulatory effect is first observed at the deepest layers and shifts with time to the more shallow layers. Thus, the reduction in consumption activity at 0.09 to $0.11 \mathrm{~cm}$ depth, owing to the lowered flux of oxidizable substrates from the upper layers and the exhaustion of the local pool of oxidizable substrates, is counterbalanced by enhanced oxygen consumption due to an increasing supply of reduced compounds from below. This increased activity is ephemeral though, since the enhanced input of reduced compounds indicates the advent of the oxic-anoxic boundary and forms the prelude to oxygen limitation.

As can be anticipated from the low oxygen concentrations and high consumption activities in the deeper layers, the onset of oxygen limitation is first observed at the bottom of the oxic layer and moves upward with time (cf. Fig. 6B). The onset of oxygen limitation in the 0.05 to $0.08 \mathrm{~cm}$ layer, though, coincides with the onset at $0.11 \mathrm{~cm}$, which may seem puzzling at first glance. The increasing activities in the 0.05 to $0.08 \mathrm{~cm}$ layer with time, however, resulted in oxygen depletion before the oxygen was removed in the 0.08 to 0.11 $\mathrm{cm}$ layer (cf. Fig. 4C). As a consequence, the 0.05 to 0.08 $\mathrm{cm}$ layer was devoid of oxygen before the enhanced flux of reduced compounds from below could exert its stimulatory effect on oxygen consumption. Thus, no enhanced oxygen consumption due to an increased flux of reduced compounds was observed at these depths briefly before the onset of oxygen limitation.

The stimulatory effect of upward diffusing compounds was most pronounced in the deepest layer, decreased at shallower depths, and finally dissipated in the intermediate layer. Until the end of the dark period no stimulation of oxygen consumption was observed in the most shallow layers. It is speculated that the immobilization and denitrification potential in the suboxic zone were strong enough to prevent the flux of reduced compounds into the oxic layer during steady state in darkness. Oxidation of reduced organic and inorganic compounds by $\mathrm{Fe}^{\mathrm{III}}, \mathrm{Mn}^{\mathrm{IV}}$, or $\mathrm{SO}_{4}^{2-}$ would result in the generation of $\mathrm{Fe}^{\mathrm{II}}, \mathrm{Mn}^{\mathrm{II}}$, and $\mathrm{H}_{2} \mathrm{~S}$, which would shuttle the reducing equivalents further to the oxic layer. Oxidation by denitrification, though, would result in redox inactive dinitrogen gas, which would not transfer reduction equivalents to the oxic layer. Since the decrease in $\mathrm{pH}$ upon darkening is generally much slower than the change in oxygen concentration (unpubl. data), the still relatively high $\mathrm{pH}$ may have resulted in the precipitation of ferrous and manganous carbonates (Hem and Lind 1983). Additionally, a high pH favors the adsorption of $\mathrm{Fe}^{\mathrm{II}}$ and $\mathrm{Mn}^{\mathrm{II}}$ to manganese-oxides. Thus, immobilization in the suboxic zone could intercede 

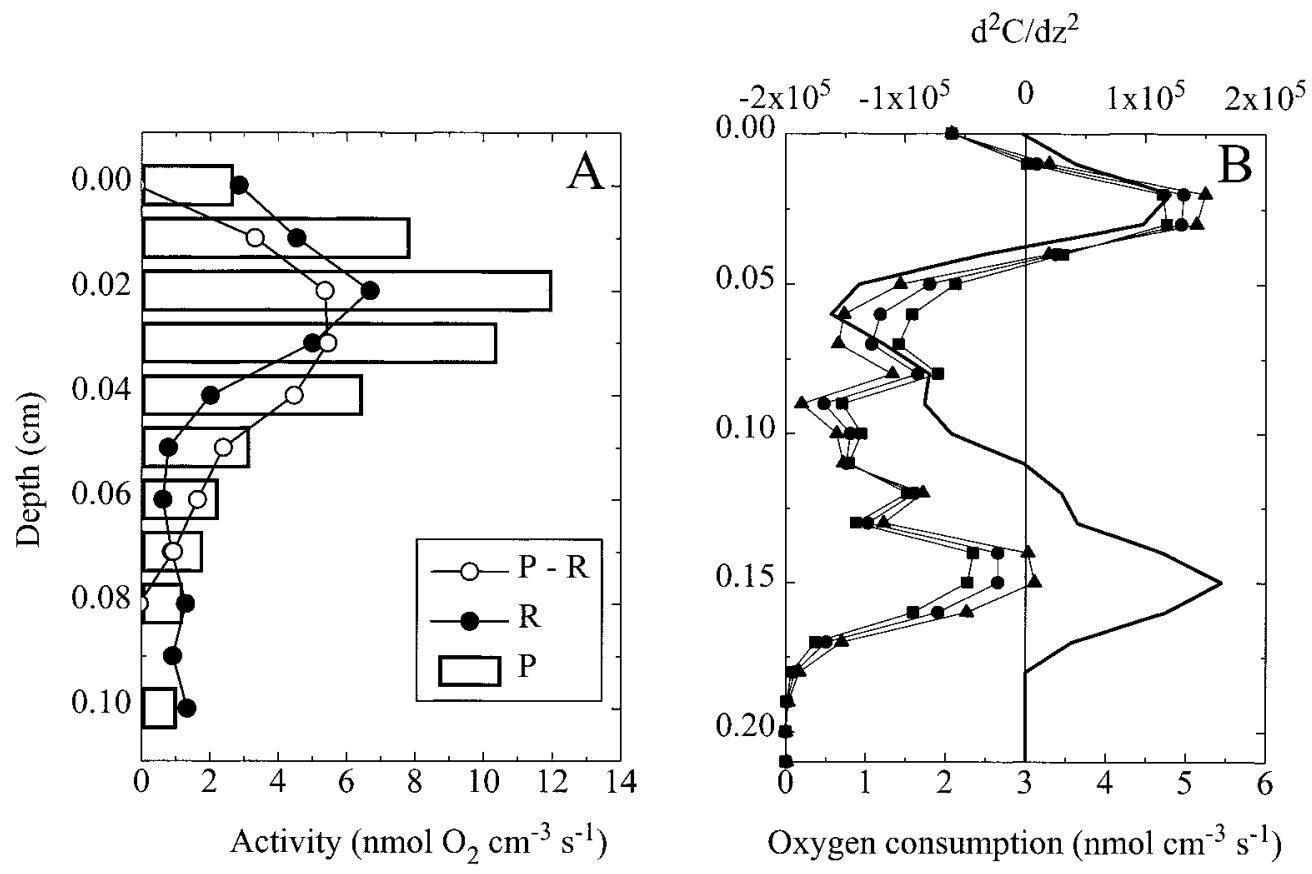

Fig. 10. (A) Depth profiles of net oxygen metabolism, of oxygen consumption, and of photosynthesis for the upper $0.1 \mathrm{~cm}$ of the mat. The photosynthesis profile was calculated by summing net oxygen metabolism and oxygen consumption. (B) Calculated activities of oxygen consumption at $60 \mathrm{~s}$ after darkening for $D_{s}$ values of $1.28 \times 10^{-5}$ (squares), $1.57 \times 10^{-5}$ (circles), and $1.93 \times$ $10^{-5} \mathrm{~cm}^{2} \mathrm{~s}^{-1}$ (triangles). The thick line represents the second-order derivative of the oxygen concentration with respect to depth.

the upward flux of $\mathrm{Fe}^{\mathrm{II}}$ and $\mathrm{Mn}^{\mathrm{II}}$ toward the oxic layer during the steady state in darkness.

The foregoing discussion underscores why the estimated affinity constants should be considered as apparent; the active biomass involved in oxygen consumption and the concentrations of both oxygen and oxidizable substrates may change with time, while all affect the estimation of maximum consumption activity and affinity constant. The apparent affinity constants estimated in the present study are somewhat higher than the values that have been determined in laboratory studies on isolated microorganisms (Hao et al. 1983). In a dynamic environment such as a microbial mat, microorganisms are expected to be adapted to the rapid changes in their chemical environment. As oxygen becomes limiting, metabolically versatile microorganisms may change to fermentation or anaerobic respiratory metabolism. These metabolic shifts will progressively reduce the biomass that is involved in the consumption of oxygen at limiting concentrations and may result in a lowering of oxygen consumption rates, giving rise to slightly higher affinity constants as compared to microbiological studies.

Net oxygen metabolism upon illumination-The interpretation of the time course of net metabolism is hampered by the lack of independent information on either the response of photosynthesis or oxygen consumption. The initial production of oxygen in deeper anoxic layers upon illumination is probably used for the oxidation of reduced compounds, generated by the anoxic metabolism of the phototrophs (e.g., fermentation) and associated microbiota. Since the reduction potential presumably increased with depth, whereas the photosynthesis potential decreased with depth, the oxic layer gradually deepened without deeper centers for oxygenation. Thus, the oxic layer increased from 0.04 to $0.16 \mathrm{~cm}$ by the concerted action of photosynthesis in the deeper, initially anoxic layers and the increasing downward flux of oxygen with time due to the development of a subsurface maximum in oxygen concentration. The expansion rate of the oxic layer was at maximum immediately after the start of illumination and slowed down with time until the steady state profile was attained. This downward movement of the oxic-anoxic interface is clearly reflected in the increasing delay in the onset of net oxygen metabolism with increasing depth (cf. Fig. 9). The increased supply of oxygen with time at a given depth is reflected in a lowering in the net oxygen metabolism due to increasing rates of oxygen consumption.

The onset and subsequent decrease in net oxygen metabolism in successively deeper layers probably resulted in a lower flux of reduced compounds into the previously oxygenated layers. As a consequence, the oxygen consumption activity in the shallower layers decreased with time, resulting in an increase in net oxygen metabolism. The rate of increase in net oxygen metabolism is depth dependent and is determined by the change in oxygen consumption activity due to the increasing supply of photosynthate from the photic layer with time and the decreasing supply of reduced compounds from below due to the oxygenation of deeper layers. The steady state value for net oxygen metabolism reflects the balance between the local rate of photosynthesis, the background value in oxygen consumption activity as determined 
by the susceptibility of the particulate reduced pool (e.g., POC and FeS) to oxidation at this depth, and the rate of oxygen consumption at steady state fluxes of photosynthate and reduced compounds from the anoxic compartment. The steady state balance of these processes resulted in positive values for net oxygen metabolism (net production of oxygen) in the photic layer down to $0.06 \mathrm{~cm}$, a negligible rate of net oxygen metabolism in the intermediate layer, and negative values in the aphotic layer.

The effect of the diffusion coefficient on activity calculations - The rates of oxygen consumption and of net oxygen metabolism are dependent on the value for $D_{s}$ as can be expected from Eq. 1 and as exemplified in Fig. 10B. An increase in $D_{s}$ will result in a lower rate of oxygen consumption if the local gradient promotes the diffusive loss from that specific depth (second derivative is negative). Conversely, an increase in $D_{s}$ will result in a higher rate if this promotes the diffusive gain of oxygen at that depth (second derivative is positive), e.g., at the bottom of the oxic layer. For net oxygen metabolism after the start of illumination, exactly the opposite is the case: an increase in $D_{s}$ yields a higher rate of net oxygen metabolism if the second derivative is negative and a lower rate if the second derivative is positive. Although the absolute level of activity is clearly affected by the diffusion coefficient, the depth trend of activity remains similar for all three tested diffusivities. Clearly, high-resolution techniques for the measurement of $D_{s}$ as a function of depth would improve the rectitude of the calculated profiles of oxygen consumption and net oxygen metabolism.

Concluding remarks-A major drawback of the method seems to be the time required to collect a complete data set of transient oxygen concentrations. This may invoke a redistribution of biomass in the mat due to migration, which may partly explain the differences in gross photosynthesis as determined by the light-dark shift technique and the present method. However, to obtain a depth distribution of gross photosynthesis and of oxygen consumption briefly after darkening requires the acquisition of oxygen concentrations during the first few seconds after darkening only. This will reduce the experimental time considerably and will limit potential artifacts. Exploring the complete transient states between dark and light, however, may indicate to which extent the different sublayers of the oxic zone are fuelled by photosynthate and by reduced compounds from anoxic layers.

The cycling technique is not limited to the study of oxygenic photosynthesis and oxygen consumption but can, with appropriate boundary conditions, be applied to other processes as well. Currently, the application to anoxygenic photosynthesis and sulphate reduction is under investigation.

Availability - The software packages used for data acquisition and for the numerical analysis are available upon request from the third and second author, respectively.

\section{References}

BAines, S. B., AND M. L. PACE. 1991. The production of dissolved organic matter by phytoplankton and its importance to bacteria:
Patterns across marine and freshwater systems. Limnol. Oceanogr. 36: 1078-1090.

BAteson, M. M., AND D. M. WARD. 1988. Photoexcretion and fate of glycolate in a hot spring cyanobacterial mat. Appl. Environ. Microbiol. 54: 1738-1743.

BAULD, J., AND T. D. BROCK. 1974. Algal excretion and bacterial assimilation in hot spring algal mats. J. Phycol. 10: 101-106.

BEARDALL, J. 1989. Photosynthesis and photorespiration in marine phytoplankton. Aquat. Bot. 34: 105-130.

BREWER, G. P. 1975. Minor elements in seawater, p. 415-496. In J. P. Riley and G. Skirrow [eds.], Chemical oceanography, v. 1. Academic.

Broecker, W. S., AND T. H. Peng. 1974. Gas exchange rates between air and sea. Tellus. 26: 21-35.

Crank, J., AND P. Nicholson. 1947. A practical method for numerical evaluation of solutions of partial differential equations of the heat-conduction type. Proc. Camb. Philos. Soc. 43: 5067.

Falkowski, P. G., Z. Dubinsky, and G. Santostefano. 1985. Light-enhanced dark respiration in phytoplankton. Verh. Internat. Verein. Limnol. 22: 2830-2833.

Glud, R. N., K. Jensen, AND N. P. Revsbech. 1995. Diffusivity in surficial sediments and benthic mats determined by use of a combined $\mathrm{N}_{2} \mathrm{O}-\mathrm{O}_{2}$ microsensor. Geochim. Cosmochim. Acta 59: 231-237.

- N. B. RAmsing, AND N. P. RevsBeCh. 1992. Photosynthesis and photosynthesis-coupled respiration in natural biofilms measured by use of oxygen microsensors. J. Phycol. 28: 51-60.

HAN, T. W., AND J. H. ELEY. 1973. Glycolate excretion by Anacystis nidulans: Effect of $\mathrm{HCO}_{3}^{-}$concentration, oxygen concentration and light intensity. Plant Cell Physiol. 14: 285-291.

HAO, O. J., M. G. RICHARD, AND D. JENKINS. 1983. The half saturation coefficient for dissolved oxygen: A dynamic method for its determination and its effect on dual species competition. Biotechnol. Bioeng. 25: 403-416.

Hem, J. D., AND C. J. Lind. 1983. Nonequilibrium models for predicting forms of precipitated manganese oxides. Geochim. Cosmochim. Acta 47: 2037-2046.

IVERSEN, N., AND B. B. JøRGENSEN. 1992. Diffusion coefficients of sulfate and methane in marine sediments: Influence of porosity. Geochim. Cosmochim. Acta 57: 571-578.

Jensen, J., AND N. P. ReVsbeCh. 1989. Photosynthesis and respiration of a diatom biofilm cultured in a new gradient growth chamber. FEMS Microbiol. Ecol. 62: 29-38.

Jensen, K., N. P. Revsbech, And L. P. Nielsen. 1993. Microscale distribution of nitrification activity in sediment determined with a shielded microsensor for nitrate. Appl. Environ. Microbiol. 59: 3287-3296.

Kühl, M., R. N. Glud, H. Ploug, and N. B. Ramsing. 1996. Microenvironmental control of photosynthesis and photosynthesis-coupled respiration in an epilithic cyanobacterial biofilm. J. Phycol. 32: 799-812.

Li, Y. H., AND S. GREGORY. 1974. Diffusion of ions in sea water and in deep-sea sediments. Geochim. Cosmochim. Acta 38: 703-714.

Lorenzen, J., R. N. Glud, And N. P. Revsbech. 1995. Impact of microsensor caused changes in diffusive boundary layer thickness on $\mathrm{O}_{2}$ profiles and photosynthetic rates in benthic communities of microorganisms. Mar. Ecol. Prog. Ser. 119: 237241.

Press, W. H., S. A. Teukolsky, W. T. Vetterling, and B. P. FlANNERY. 1992. Numerical recipes (in Fortran), 2nd ed. Cambridge Univ. Press.

Rasmussen, H., AND B. B. JøRGensen. 1992. Microelectrode studies of seasonal oxygen uptake in a coastal sediment: Role of molecular diffusion. Mar. Ecol. Prog. Ser. 81: 289-303. 
Revsbech, N. P. 1989. An oxygen microelectrode with a guard cathode. Limnol. Oceanogr. 34: 474-478.

, AND B. B. JøRGENSEN. 1983. Photosynthesis of benthic microflora measured with high spatial resolution by the oxygen microprofile method: Capabilities and limitations of the method. Limnol. Oceanogr. 28: 749-756.

, - AND O. BRIX. 1981. Primary production of microalgae in sediments measured by oxygen microprofile, $\mathrm{H}^{14} \mathrm{CO}_{3}^{-}$fixation, and oxygen exchange methods. Limnol. Oceanogr. 26: 717-730.

, B. Madsen, And B. B. JøRGEnsen. 1986. Oxygen production and consumption in sediments determined at high spa- tial resolution by computer simulation of oxygen microelectrode data. Limnol. Oceanogr. 31: 293-304.

Richtmyer, D. D., AND K. W. MoRTon. 1967. Difference methods for initial value problems. Interscience.

Stumm, W., And G. F. LeE. 1961. Oxygenation of ferrous iron. Ind. Eng. Chem. 53: 143-156.

WANNINKHOF, R. 1992. Relationship between wind speed and gas exchange over the ocean. J. Geophys. Res. 97(5): 7373-7382.

Received: 29 October 1998

Accepted: 12 July 1999 Amended: 9 August 1999 